\title{
Images of the Laser Entrance Hole from the Static X-ray Imager at NIF
}

M. Schneider, O. Jones, N. Meezan, J. Milovich, R. Town, S. Alvarez, R. Beeler, D. Bradley, J. Celeste, S. Dixit, M. Edwards, M. Haugh, D. Kalantar, J. Kline, G. Kyrala, O. Landen, B. MacGowan, P. Michel, J. Moody, S. Oberhelman, K. Piston, M. Pivovaroff, L. Suter, A. Teruya, C. Thomas, S. Vernon, A. Warrick, K. Widman, R. Wood, B. Young

May 13, 2010

High Temperature Plasma Diagnostics 2010 Wildwood, NJ, United States May 16, 2010 through May 20, 2010 
This document was prepared as an account of work sponsored by an agency of the United States government. Neither the United States government nor Lawrence Livermore National Security, LLC, nor any of their employees makes any warranty, expressed or implied, or assumes any legal liability or responsibility for the accuracy, completeness, or usefulness of any information, apparatus, product, or process disclosed, or represents that its use would not infringe privately owned rights. Reference herein to any specific commercial product, process, or service by trade name, trademark, manufacturer, or otherwise does not necessarily constitute or imply its endorsement, recommendation, or favoring by the United States government or Lawrence Livermore National Security, LLC. The views and opinions of authors expressed herein do not necessarily state or reflect those of the United States government or Lawrence Livermore National Security, LLC, and shall not be used for advertising or product endorsement purposes. 


\title{
Images of the Laser Entrance Hole from the Static X-ray Imager at NIF ${ }^{a}$
}

\author{
M. B. Schneider ${ }^{1 b)}$, O.S. Jones ${ }^{1}$, N.B. Meezan ${ }^{1}$, J.L. Milovich ${ }^{1}$, R.P. Town ${ }^{1}$, S.S. Alvarez ${ }^{1}$, R.G. \\ Beeler $^{1}$, D.K. Bradley ${ }^{1}$, J. R. Celeste ${ }^{1}$, S.N. Dixit ${ }^{1}$, M.J. Edwards ${ }^{1}$, M.J. Haugh ${ }^{2}$, D. H. Kalantar ${ }^{1}$, \\ J.L. Kline ${ }^{3}$, G.A. Kyrala ${ }^{3}$, O.L. Landen ${ }^{1}$, B.J. MacGowan ${ }^{1}$, P. Michel ${ }^{1}$, J.D. Moody ${ }^{1}$, S. K. \\ Oberhelman $^{1}$, K.W. Piston ${ }^{1}$, M.J. Pivovaroff ${ }^{1}$, L. J. Suter ${ }^{1}$, A.T. Teruya ${ }^{1}$, C.A. Thomas ${ }^{1}$, S.P. \\ Vernon $^{1}$, A.L. Warrick ${ }^{1}$, K. Widmann ${ }^{1}$, R.D. Wood ${ }^{1}$, B.K. Young ${ }^{1}$ \\ ${ }^{1}$ Lawrence Livermore National Laboratory, P.O. Box 808, Livermore, CA 94551-0808 USA \\ ${ }^{2}$ National Security Technologies, PO Box 2710, Livermore, CA 94550 USA \\ ${ }^{3}$ Los Alamos National Laboratory, Los Alamos, NM 87545 USA
}

(Presented XXXXX; received XXXXX; accepted XXXXX; published online XXXXX)

The Static X-ray Imager (SXI) at the National Ignition Facility (NIF) is a pinhole camera using a CCD detector to obtain images of hohlraum wall $\mathrm{x}$-ray drive illumination patterns seen through the laser entrance hole (LEH). Carefully chosen filters combined with the CCD response allows recording images in the $\mathrm{x}$-ray range of 3 to $5 \mathrm{keV}$ with $60 \mu \mathrm{m}$ spatial resolution. The routines used to obtain the apparent size of the backlit $\mathrm{LEH}$, and the location and intensity of beam spots are discussed and compared to predictions. A new soft xray channel centered at $870 \mathrm{eV}$ (near the $\mathrm{x}$-ray peak of a $300 \mathrm{eV}$ temperature ignition hohlraum) is discussed.

\section{Introduction}

The goal of experiments at the National Ignition Facility $(\mathrm{NIF})^{1}$ is to achieve ignition through the indirect drive technique. ${ }^{2}$ Figure 1 shows a schematic of the target and laser beams used to study the energetics and drive symmetry of the hohlraum design. ${ }^{3}$ The target is a gas-filled, cryogenic hohlraum with a plastic capsule at its center. The capsule is filled with helium gas (often doped with deuterium $)^{3-4}$ Ninety-six laser beams, sixty-four in outer cones $\left(50^{\circ}, 44.5^{\circ}\right)$ and thirty-two in inner cones $\left(30^{\circ}, 23.5^{\circ}\right)$ enter the laser entrance holes (LEH) at each end of the hohlraum in 11 to $20 \mathrm{~ns}$ shaped pulses with total energies ranging from 500 $\mathrm{kJ}$ to $\sim 1 \mathrm{MJ}$ with wavelength $351 \mathrm{~nm}$. The laser energy is converted into $\mathrm{x}$-ray energy via the inverse bremsstrahlung interaction with the gas fill or the high-Z hohlraum walls. The $\mathrm{X}$ ray drive heats and ablates the outer shell of the capsule, thereby compressing the inner core. ${ }^{2-4}$ To achieve ignition with minimal amount of laser energy, the capsule must be compressed symmetrically. ${ }^{2-4}$ It is important to be able to model the intensity and symmetry of the radiation drive onto the capsule.

The Static X-ray Imager $(\mathrm{SXI})^{5}$ captures time-integrated pictures of the inside of the hohlraum as viewed through the LEH. Its observation angle is $18^{\circ}$ (upper SXI) or $19^{\circ}$ (lower SXI) to the hohlraum axis (Figure 1). The images provide information on the backlit size of the LEH and on the positions and intensities of the laser beams interacting with the high- $Z$ plasma of the wall. This information is compared with models to understand the radiation drive onto the capsule.

We describe here the data analysis techniques that obtain: 1) The size of the backlit LEH calculated from lineouts and radial distribution functions; 2) A 2 dimensional version of the image to compare with 2D models; and 3) The fluence (counts/pixel) in the "outer" beams which enter the hohlraum from the opposite ("far") LEH.

${ }^{\text {a) }}$ Contributed paper published as part of the Proceedings of the 18th Topical Conference on High-Temperature Plasma Diagnostics, Wildwood, New Jersey, May, 2010. b) Author to whom correspondence should be addressed. Electonic mail: schneider5@1lnl.gov

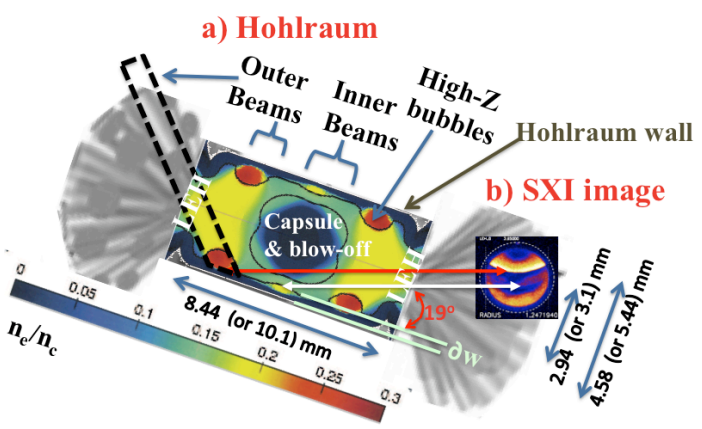

Figure 1: (Color online) Schematic of the experimental set-up. The hohlraum axis is tilted 190 to SXI image. a) Sketch of hohlraum showing laser beams (on outside) and HYDRA ${ }^{3}$ simulation of electron temperature (on inside). The places where the beams hit the wall at early time are identified. Not shown is the trajectory of the laser beams inside the hohlraum. One outer beam is shown in dashes to illustrate that a high- $Z$ bubble is formed where the outer beams hit the wall. b) Typical SXI image: The red arrow connects the feature in the SXI image to the high$\mathrm{Z}$ bubble. The white arrow connects an inner beam feature in the SXI image to the spots where inner beams hit the hohlraum wall.

\section{The SXI diagnostic}

The $\mathrm{SXI}^{5}$ diagnostic is operated at $2 \mathrm{X}$ magnification with the detector situated at $4.97 \mathrm{~m}$ from the target. The detector is an 
x-ray sensitive, thinned, back-illuminated silicon $\mathrm{CCD}{ }^{6}$ The silicon substrate is $15 \mu \mathrm{m}$ thick, with $24 \mu \mathrm{m}$ square pixels in a $2 \mathrm{k}$ $\mathrm{x} 2 \mathrm{k}$ array. The detector is absolutely calibrated. ${ }^{6}$ Figure $2 \mathrm{a}$ shows the quantum efficiency (fraction of photons detected per incident photons) of the CCD. Figure $2 b$ shows the response of the $\mathrm{CCD}$, the digital number (DN) of counts per photon per pixel. The SXI is configured with four $25 \mu \mathrm{m}$ diameter pinholes which are differentially filtered to provide a high dynamic range. Figure $2 \mathrm{c}$ shows the channel response for the channel with $75 \mu \mathrm{m}$ beryllium and $50 \mu \mathrm{m}$ titanium filters. This channel detects $\mathrm{x}$-rays from 3 to $5 \mathrm{keV}$ with a spatial resolution of $\sim 60 \mu \mathrm{m}$. The pinhole diameter is chosen so that the contributions of diffraction and geometry are about equal in this x-ray range.
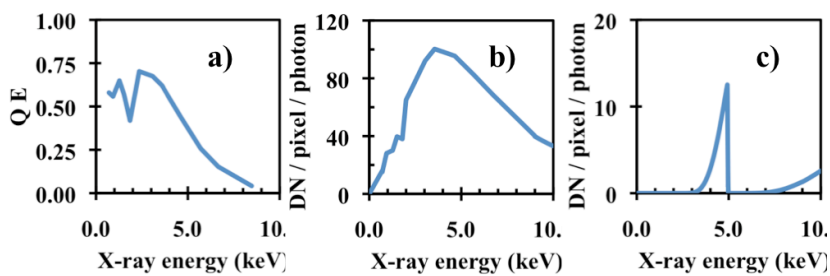

Figure 2: SXI CCD vs X-ray energy: (a) Quantum efficiency (QE); (b) CCD response: counts or digital number (DN) per photon per pixel and (c) Response of the $3-5 \mathrm{keV}$ channel.

\section{Data Analysis}

Figure 3 identifies the features in the SXI image. The original size of the LEH is the dashed line.

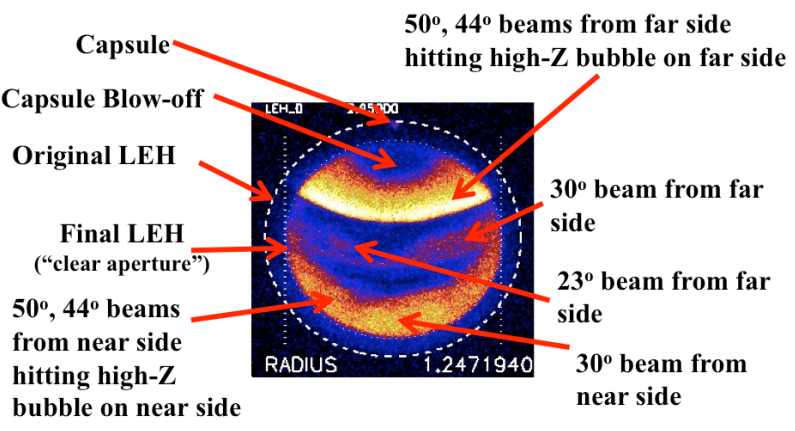

Figure 3: Identification of features in the SXI image.

\section{A. LEH size}

The SXI diagnostic has become an important tool to ascertain the final LEH size (or "clear aperture") which is used in determining the radiation drive at the capsule. To accomplish this, the centroid of the backlit LEH is first determined from vertical and horizontal lineouts, (plotted vs. distance in the target plane). To reduce noise, the lineouts are averaged over a strip 0.3 $\mathrm{mm}$ wide. The edges of the LEH are defined as the midpoints of the steepest slopes in the LEH region of the lineouts. The center of the LEH is the midpoint of the found edges. If the top of the LEH cannot be seen in the lineout due to the dim capsule blowoff, then the top of the LEH is identified by eye from the image.
The time-integrated size of the LEH is obtained in two ways. Method 1 takes the $0.3 \mathrm{~mm}$ wide horizontal lineout through the center of the LEH. Figure 4a plots this lineout. Method 2 plots the radial distribution function, which is calculated as follows: First, if there is a capsule visible, the region of the capsule is replaced by an equivalent area taken from a nearby region of the image. Second, the image is made circular by stretching it vertically around the LEH center by $1 / \cos \left(19^{\circ}\right)$ (or $18^{\circ}$ for Upper SXI). Finally the average counts in circular rings about the center of the LEH are calculated. The radial distribution function (RDF) is also plotted in Figure 4a. The LEH size is the average of the midpoints of the steep slope of the horizontal lineout and the RDF in the LEH region. Figure 5a plots the LEH over the original SXI image for a $640 \mathrm{~kJ}, 20 \mathrm{~ns}$ shot using a $5.44 \mathrm{~mm}$ diameter hohlraum. Figure $5 \mathrm{c}$ shows a radiation-hydrodynamics simulation of this shot using the LASNEX $^{7}$ code. The simulations show a smaller LEH radius than measured by about 0.15 $\mathrm{mm}$.

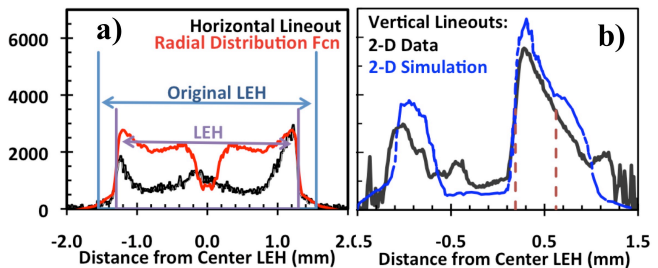

Figure 4: Lineouts: a) Horizontal lineout (black) and radial distribution function (red) used to obtain the size of the LEH. b) Vertical lineout (black) from the 2D image (Fig. 5b) and from the simulation (blue) shown in Fig. 5.

The fluence in the outer beams is the average counts in the region between the dashed red lines (which show the full width at $70 \%$ maximum in the outer beam feature.)

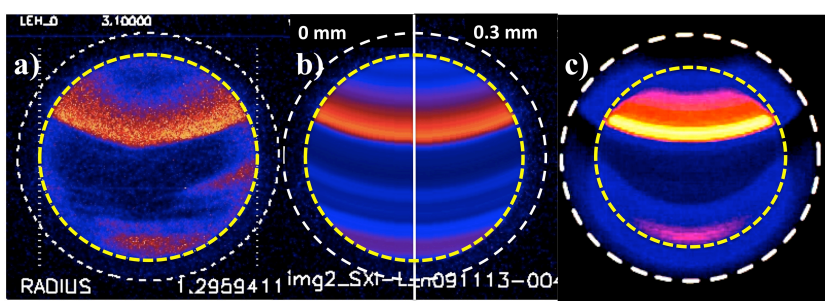

Figure 5: Comparison to modeling: a) SXI data image b) 2D version of data (with $0 \mathrm{~mm}$ wall motion on left half and $0.3 \mathrm{~mm}$ wall motion on right half); c) $2 \mathrm{D} \mathrm{LASNEX}^{7}$ simulation. The vertical lineouts from $\mathrm{b}$ ) and c) are plotted in Figure 4b. The white dashed circles show the original size of the LEH. The yellow dashed circles show the clear aperture (final size of the LEH) The simulation show similar counts in features (Figure $4 \mathrm{~b}$ ) but the clear aperture is smaller. Note that the FAR inner beams are distinct in the data but are mixed with the NEAR beam feature in the simulation.

\section{B. 2D Image}

The SXI image shown in Figure $1 \mathrm{~b}$ and Figure 3 has threedimensional features such as the $30^{\circ}$ and $23.5^{\circ}$ beam spots from the far side. To compare with two-dimensional (2D) models such as LASNEX ${ }^{7}$, a $2 \mathrm{D}$ version of the SXI image is constructed by performing an azimuthal average. If we assume that all features in the SXI image originate at the hohlraum wall, then, for each " $z$ " position along the hohlraum axis, we average over all pixels visible in the SXI image which belong in the ring at that " $\mathrm{z}$ " 
position. The 2D image is created only from the region inside the LEH (the "clear aperture" of the SXI image). The counts of all pixels outside the clear aperture is set equal to 0 , and then the SXI image is stretched by $1 / \cos \left(19^{\circ}\right.$ ) (or $18^{\circ}$ for Upper SXI) about the center of the LEH to make the image circular. The center of the LEH is $(x, y)=(0,0)$. If the radius of the hohlraum wall is R', then in the stretched image, all pixels on the same ring will lie on a circular arc with radius $R^{\prime}$ and centered at $(x, y)=(0$, $\left.\mathrm{R}^{\prime}+\partial \mathrm{y}\right)$ where $\partial \mathrm{y}$ is the displacement along the vertical axis $(x=0)$ from the center of the $L E H$. If $\mathrm{R}$ is the original radius of the hohlraum, and $\partial \mathrm{w}$ is the time-averaged movement of the wall that reduced this radius, then $\mathrm{R}^{\prime}=\mathrm{R}-\partial \mathrm{w}$. In the $2 \mathrm{D}$ image, all pixels on the same circular are set equal to the average count of all pixels on this circular arc. The final 2D image is created by reverting to the initial image size (i.e. shrink the vertical axis by $\left.\cos \left(19^{\circ}\right)\right)$. Figure $5 \mathrm{~b}$ shows the resulting $2 \mathrm{D}$ image after this procedure (with $\partial \mathrm{w}=0$ wall motion on the left and $\partial \mathrm{w}=0.3 \mathrm{~mm}$ wall motion on the right). Since both halves of the image are almost identical, the wall motion does not have a big effect on this construction. Figure 1 illustrates how the wall motion is estimated from the sharp edge on the lower end of the "far outer" beam feature in the SXI image. This feature is due to outer beams hitting the high- $Z$ bubble. We model an outer beam by a rectangle that goes through the center of the far LEH at a $47.5^{\circ}$ angle (the thick dashed line in Fig 1a marked "outer beam"). This "beam" terminates at the wall, so the intersection of the center of this beam with the horizontal line tangent to the SXI feature (red line) gives the wall position. In this simple model, the wall motion is 0.1 to $0.15 \mathrm{~mm}$ for the data discussed in Ref 3 .

\section{Counts in Far Outer Beam Feature}

The NIF experiments ${ }^{3,4}$ have shown that energy transfer between inner and outer beams can be tuned by changing the wavelength difference between the laser cones (inner and outer), as predicted by theory ${ }^{8}$. Reference 4 plotted the capsule symmetry vs wavelengths shift, $\Delta \lambda$. Figure 6 a plots the average counts in the outer beams for identical shots except for the value of $\Delta \lambda$. The fluence, or average counts in the far outer beams is defined as the average counts between the two $70 \%$ of full maximum points in the vertical lineout in Figure $4 \mathrm{~b}$. Figure $6 \mathrm{~b}$ is the capsule symmetry plot for these shots. Figure $6 a$ shows the energy transfer from the outer beams to the inner beams increases with increasing $\Delta \lambda$. This procedure was employed to improve the capsule symmetry. 3,4
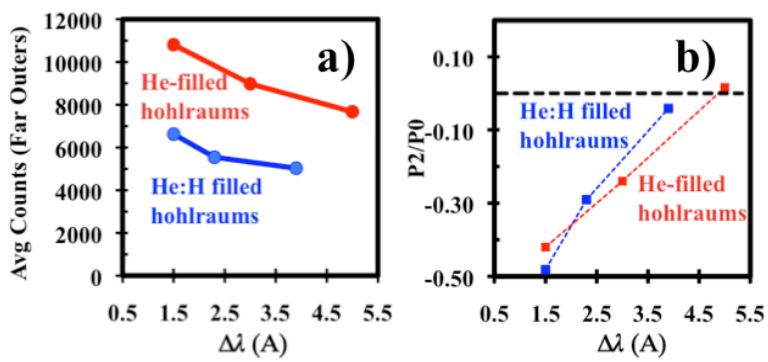

Figure 7: Evidence of energy transfer from outer beams to inner beams with increasing $\Delta \lambda$ : a) The average counts in the outer beams decrease as $\Delta \lambda$ increases. b) The symmetry of capsule goes from prolate to round as $\Delta \lambda$ increases.

\section{Future directions}

The images in Figure 5 show that the simulations predict a smaller LEH radius than observed in the data. The SXI image is from a 3 to $5 \mathrm{keV}$ x-ray band. To more accurately determine the capsule drive we have designed an additional channel with an $\mathrm{x}$ ray band centered at $870 \mathrm{eV}$, near the peak of the thermal $\mathrm{x}$-ray flux of a $300 \mathrm{eV}$ blackbody. The channel uses a multilayer mirror composed of 30 layers of tungsten (W) alternating with equal thickness of boron carbide (B4C). The periodicity is $43.1 \mathrm{~A}$ and the angle of incidence is $10^{\circ}$. The configuration uses a 45 $\mu \mathrm{m}$ pinhole, and $2 \mu \mathrm{m}$ copper plus $0.5 \mu \mathrm{m}$ polyimide filter. The channel will be fielded this summer.

\section{Acknowledgements}

We thank the NIF operations, laser performance, target diagnostics, data analysis, data visualization, and target fabrication teams. This work was performed under the auspices of the U.S. Department of Energy by Lawerence Livermore National Laboratory under Contract No. DE-AC52-07NA27344 and by Los Alamos National Laboratory under Contract No. DEAC52-06NA25396.

1 E. I. Moses, R. N. Boyd, B. A. Remington, C. J. Keane, and R. Al-Ayat, Phys. Plasmas 16, 041006 _2009_.

2 J. D. Lindl, P. Amendt, R. L. Berger, S. G. Glendinning, S. H. Glenzer, S.W. Haan, R. L. Kauffman, O. L. Landen, and L. J. Suter, Phys. Plasmas 11, $339 \_2004$

3 N. B. Meezan, L. J. Atherton, D. A. Callahan, E. L. Dewald, S. Dixit, E. G. Dzenitis, M. J. Edwards, C. A. Haynam, D. E. Hinkel, O. S. Jones, O. Landen, R. A. London, P. A. Michel, J. D. Moody, J. L. Milovich, M. B. Schneider, C. A. Thomas, R. P. J. Town, A. L. Warrick, S. V. Weber, K. Widmann, S. H. Glenzer, L. J. Suter, B. J. MacGowan, J. L. Kline, G. A. Kyrala, and A. Nikroo, Phys. Plasmas 17, $056304 \_2010 \_$.

4 S. H. Glenzer, B. J. MacGowan, P. Michel, N. B. Meezan, L. J. Suter, S. N. Dixit, J. L. Kline, G. A. Kyrala, D. K. Bradley, D. A. Callahan, E. L. Dewald, L. Divol, E. Dzenitis, M. J. Edwards, A. V. Hamza, C. A. Haynam, D. E. Hinkel, D. H. Kalantar, J. D. Kilkenny, O. L. Landen, J. D. Lindl, S. LePape, J. D. Moody, A. Nikroo, T. Parham, M. B. Schneider, R.P. J. Town, P. Wegner, K. Widmann, P. Whitman, B. K. F. Young, B. Van

Wonterghem, L. J. Atherton, and E. I. Moses, Science 327, 1228 _2010_. 5 M. D. Landon, J. A. Koch, S. S. Alvarez, P. M. Bell, F. D. Lee, and J. D. Moody, Rev. Sci. Instrum. 72, $698 \_2001$

6M. J. Haugh and M. B. Schneider, Rev. Sci. Instrum. 79, 10E925 _2008_.

7 G.B. Zimmerman and W.L. Kruer, Comments Plasma Phys. Control. Fusion 285 (1975)

8 P. Michel, L. Divol, E. A. Williams, C. A. Thomas, D. A. Callahan, S. Weber, S. W. Haan, J. D. Salmonson, N. B. Meezan, O. L. Landen, S. Dixit, D. E. Hinkel, M. J. Edwards, B. J. MacGowan, J. D. Lindl, S. H. Glenzer, and L. J. Suter, Phys. Plasmas 16, 042702 _2009_ 